Int. J. Electrochem. Sci., 15 (2020) $94-108$

International Journal of

ELECTROCHEMICAL

SCIENCE

www.electrochemsci.org

\title{
Modelling of Geometric Features of Micro-Channel Made using Abrasive Assisted Electrochemical Jet Machining
}

\author{
Changshui Gao ${ }^{£}$, Zhuang Liu, , Yi Qiu, Kai Zhao \\ College of Mechanical and Electrical Engineering, Nanjing University of Aeronautics and \\ Astronautics, 29 Yudao Street, Nanjing 210016, China; \\ ${ }^{£}$ These authors contributed equally to this work and should be considered co-first authors \\ *E-mail: liuzhuang@,nuaa.edu.cn
}

doi: $10.20964 / 2020.01 .24$

Received: 6 August 2019 / Accepted: 6 October 2019 / Published: 30 November 2019

Geometric features of micro-channel can significantly affect heat transfer rate or fluid mixing rate in applications where the micro-channels are functioning. Abrasive assisted electrochemical jet machining (AECJM) can machine complex micro-channels at metals with low-cost, high efficiency and good surface quality. This study presented a method for predicting channel width and channel depth machined using AECJM process. Two different models, namely quadratic polynomial model and dimensional analysis model, for predicting width and depth of micro-channel due to AECJM were developed and investigated. The result shows that the dimensional analysis model has more stable predictability than quadratic polynomial model. Jet diameter is the dominant factor affecting the channel width, while working voltage and machining time are main factors influencing the channel depth. The inter-relationship between channel width and channel depth can be expressed using presented predictive models. Afterwards, micro-channel with desired width and depth can be achieved through the inter-relationship and present models.

Keywords: micro-channel; geometric features; abrasive assisted electrochemical jet machining; electrochemical jet machining; abrasive water jet machining

\section{FULL TEXT}

(C) 2020 The Authors. Published by ESG (www.electrochemsci.org). This article is an open access article distributed under the terms and conditions of the Creative Commons Attribution license (http://creativecommons.org/licenses/by/4.0/). 